\title{
Corrosion Behavior of Al-3.0 wt.\%Mg Alloy by Cold-Drawing Process
}

\author{
Xin Zhang ${ }^{1,2}$, Zehua Wang, ${ }^{1, *}$ Zehua Zhou ${ }^{1}$, Jing Cao ${ }^{1}$, Guangheng Yang ${ }^{1}$ \\ ${ }^{1}$ College of Mechanics and Materials, Hohai University, Nanjing, 210098, China \\ ${ }^{2}$ Nantong Ocean and Offshore Engineering Research Institute, Hohai University, Nantong, 226300, \\ China \\ *E-mail: zhangxin.007@163.com
}

doi: $10.20964 / 2020.02 .54$

Received: 1 October 2019 / Accepted: 2 December 2019 / Published: 31 December 2019

In this study, the evolution of cold-drawn corrosion behavior of $\mathrm{Al}-3.0 \mathrm{wt} . \% \mathrm{Mg}$ alloy was investigated by microstructure observation, immersion test and electrochemical measurement. Results indicated that, during the cold drawing process, the equiaxial grains of alloy were elongated and pressed into fibrous and globular grains on longitudinal section ( I ) and cross section ( II ), respectively. Meanwhile, the large size skeletal $\mathrm{FeAl}_{3}$ phase particles were elongated and fragmented into small size lining particles on I section, and pressed into small globular particles on II section. As the strain increased, the corrosion resistance increased and the pitting sensibility decreased, while the corrosion sensibility increased first and then decreased. Finally, compared to the alloy on longitudinal section, the alloy on cross section revealed better corrosion resistance and lower pitting sensibility.

Keywords: cold-drawing process Al-3.0 wt.\%Mg alloy, corrosion behavior, pitting corrosion.

\section{FULL TEXT}

(C) 2020 The Authors. Published by ESG (www.electrochemsci.org). This article is an open access article distributed under the terms and conditions of the Creative Commons Attribution license (http://creativecommons.org/licenses/by/4.0/). 